\title{
Jogos de Programar como uma Abordagem para os Primeiros Contatos dos Estudantes com a Programação
}

\author{
Guilherme A. Zanchett', Adilson Vahldick ${ }^{3,4}$, André Raabe ${ }^{1,2}$ \\ 'Mestrado em Computação Aplicada \\ 2Programa de Pós-Graduação em Educação \\ Universidade do Vale do Itajaí (UNIVALI) - Itajaí, SC - Brasil \\ ${ }^{3}$ Departamento de Engenharia de Software \\ Universidade do Estado de Santa Catarina (UDESC) - Ibirama, SC - Brasil \\ ${ }^{4}$ Departamento de Engenharia Informática - Universidade de Coimbra - Portugal \\ guizanchett@gmail.com, adilson.vahldick@udesc.br, raabe@univali.br
}

\begin{abstract}
This work investigates the use of programming games as an alternative to establishing the first contacts of high school students with programming concepts. Programming games are puzzle style games where the player must solve problems that require algorithmic logic using some programming representation. The research was conducted with 14 students who used three different games and answered a questionnaire with open and closed questions that sought to know the opinion of students on: (i) favorite game, (ii) engagement and fun, (iii) tutorial style (how the games bring the problems to the players); and (iv) perception of programming and concepts involved. The results indicate that using programming games as an approach in the early contacts of the students with programming concepts can bring beneficial results for creating a less intimidating environment where the student realizes his ability to achieve educational goals while have fun.
\end{abstract}

Resumo: Este trabalho investiga a utilização de jogos de programar como forma de estabelecer os primeiros contatos de estudantes de ensino médio com conceitos de programação. Jogos de programar são jogos do estilo puzzle em que o jogador deve solucionar problemas que requerem lógica algorítmica usando alguma notação de programação. A pesquisa foi realizada com 14 estudantes que utilizaram três diferentes jogos de programar e responderam um questionário com perguntas abertas e fechadas que buscaram conhecer a opinião dos estudantes sobre: (i) jogo preferido, (ii) engajamento e diversão, (iii) estilo tutorial (forma de propor os problemas aos jogadores); e (iv) percepção sobre programação e conceitos envolvidos. Os resultados indicam que a abordagem de uso de jogos de programar nos contatos iniciais dos estudantes podem trazer resultados benéficos ao criar um ambiente menos intimidador em que o estudante se percebe capaz de atingir seus objetivos educacionais enquanto se diverte.

\section{Introdução}

O primeiro contato dos estudantes com conceitos de programação pode ser determinante na forma como eles perceberão os desafios e enfrentarão as dificuldades inerentes à aprendizagem da lógica de programação. Segundo Rogerson e Scott (2010), fatores psicológicos como motivação pessoal e autoconfiança exercem grande influência sobre alunos de programação pois estes estão diante da necessidade de dominar uma forma 


\section{CBIE-LACLO 2015}

Anais dos Workshops do IV Congresso Brasileiro de Informática na Educação (CBIE 2015)

completamente nova de pensar. Kinnunen et al. (2007) ressaltam que programação requer um alto nível de abstração, prática e um esforço intenso. Gomes e Mendes (2007) destacam a motivação como um dos fatores principais para o sucesso, principalmente devido ao fato de que muitos alunos possuem uma visão negativa associada à programação e aos programadores, que são em boa parte vistos como pessoas antissociais ou introspectivas. Orehovački e Babić (2015) afirmam que 60\% dos alunos de cursos de engenharia gostariam que disciplinas de programação fossem mais interativas, amigáveis e divertidas.

Neste contexto, o trabalho busca investigar a utilização de jogos de programar como forma de estabelecer os primeiros contatos de estudantes de ensino médio com conceitos de programação. Jogos de programar são jogos do estilo puzzle em que o jogador deve solucionar problemas que requerem lógica algoritmica usando alguma notação de programação (De Jesus, Raabe, 2010). À medida que soluciona os problemas avança para novas fases, onde os conceitos são reforçados, ou novos conceitos são apresentados.

Foram testados três jogos de programar com diferentes enredos e notações de programação, buscando conhecer a opinião dos estudantes sobre: (i) jogo preferido, (ii) engajamento e diversão, (iii) estilo tutorial (forma de propor os problemas aos jogadores); e (iv) percepção sobre programação e conceitos envolvidos. A compreensão sobre a forma como estes jogos são percebidos pelos estudantes auxilia no planejamento de atividades de introdução ao pensamento computacional, possibilitando também delinear diretrizes para a concepção e o projeto de novos jogos.

O artigo está organizado como segue: a Seção 2 apresenta os procedimentos metodológicos detalhando os jogos utilizados e o instrumento de mensuração construído (questionário). A Seção 3 apresenta os resultados e a Seção 4 as conclusões do trabalho.

\section{Procedimentos Metodológicos}

Os sujeitos participantes da pesquisa foram 14 estudantes (6 meninas e 8 meninos) que fazem parte de um projeto de extensão voltado à introdução do pensamento computacional envolvendo ensino de programação e robótica. Os estudantes são do $1^{\circ} \mathrm{e}$ $2^{\text {o }}$ anos do ensino médio de uma escola pública e foram selecionados pela direção da escola devido ao bom desempenho acadêmico.

Três jogos de programar foram utilizados como primeira atividade de contato dos estudantes com conceitos de programação. Foram selecionados os seguintes jogos que usam diferentes notações de programação: (i) Code Combat $^{1}$ que utiliza notação de código textual; (ii) Lightbot ${ }^{2}$ que utiliza sequenciamento de blocos de instruções; e (iii) NoBug's Snack Bar ${ }^{3}$ que utiliza a notação de blocos similares ao da ferramenta Scratch. Os jogos são detalhados na seção 2.1.

Os estudantes foram divididos em duas turmas de sete individuos que participaram do projeto em dias intercalados. Durante três semanas cada turma jogou por aproximadamente 4 horas cada um dos jogos. Explicações complementares foram feitas sempre que os estudantes solicitavam ou que a turma como um todo demonstrava alguma dificuldade de compreensão. Não houveram explicações prévias sobre conceitos de programação de forma que o uso dos jogos representou um primeiro contato dos estudantes com o tema. E a partir deste uso as explicações eram fornecidas conforme as dúvidas surgiam. Após as três semanas de experimentação com os três jogos, foi

\footnotetext{
${ }^{1}$ http://www.codecombat.com

2 http://www.lightbot.com

${ }^{3}$ http://nobugssnackbar.dei.uc.pt/
} 
aplicado um questionário com perguntas abertas e fechadas que é detalhado na seção 2.2 .

\subsection{Jogos Selecionados}

A escolha dos jogos foi feita considerando diversos critérios. Os jogos deveriam abordar conceitos de programação como variáveis, loops, desvios e funções. Deveriam possuir diferentes notações de programação (logo, blocos, código) diferentes enredos e formas de propor os problemas aos jogadores (que foram denominados de estilos tutoriais). Como o estudo foi realizado com estudantes do ensino médio, jogos com linguagem visual voltada ao público infantil foram excluidos. Da mesma forma, jogos que tinham custo de aquisição também foram excluidos. Os jogos foram identificados a partir do trabalho de Vahldick, Mendes e Marcelino (2014). Os três jogos selecionados são detalhados a seguir.

\subsubsection{Code Combat}

O Code Combat é um jogo que aborda conceitos de programação através de uma aventura medieval, onde o jogador controla heróis, e ao longo de sua jornada vai coletando cristais, e derrotando diversos inimigos, como ogros, bandidos, entre outros. É um jogo gratuito, que também disponibiliza fases pagas. Estas fases não são obrigatórias e não influenciam diretamente no progresso do jogo. $\mathrm{O}$ jogo disponibiliza uma IDE própria para que o jogador implemente seus códigos. Esta IDE trabalha com 6 linguagens de programação, sendo elas: Python, JavaScript, CofeeScript (Experimental), Clojure (Experimental), Lua e IO (Experimental). O jogador pode escolher entre 23 idiomas na página inicial do site do jogo. O jogo é dividido em 6 mundos, dentre eles 5 disponíveis com 165 fases gratuitas.

Cada mundo fornece uma estimativa de tempo necessário para sua conclusão. Os conceitos abordados e as informações a respeito de cada mundo estão dispostos na Tabela 1.

\begin{tabular}{|c|c|c|c|}
\hline Mundo & $\begin{array}{c}\text { Quantidade de } \\
\text { Fases }\end{array}$ & $\begin{array}{c}\text { Tempo de Conclusão } \\
\text { Estimado }\end{array}$ & Conceitos Abordados \\
\hline $\begin{array}{c}\text { Kithgard } \\
\text { Dungeon }\end{array}$ & 34 & $1-3$ horas & Sintaxe, métodos, parâmetros, strings, loops e variáveis \\
\hline $\begin{array}{c}\text { Backwoods } \\
\text { Forest }\end{array}$ & 45 & $2-6$ horas & $\begin{array}{c}\text { Desvios condicionais, operadores relacionais, propriedades de } \\
\text { objetos e manuseio de inputs }\end{array}$ \\
\hline $\begin{array}{c}\text { Sarven Desert } \\
\text { (loudrip } \\
\text { Mountain }\end{array}$ & 37 & $4-11$ horas & $\begin{array}{c}\text { Operadores aritiméticos, loops-while, arrays, comparação de } \\
\text { strings, encontrar min/max }\end{array}$ \\
\hline $\begin{array}{c}\text { Kelvinthap } \\
\text { Glacier }\end{array}$ & 41 & N/D & Object-literals, invocação remota de métodos, for-loops, \\
funços, desenho e módulo
\end{tabular}

Tabela 1. Informações sobre os mundos do Code Combat

Os dois últimos mundos ainda estão em desenvolvimento e abordam o que o jogo denomina de técnicas avançadas, entretanto não deixa claro quais são estas técnicas. O quinto mundo é acessível, enquanto o sexto não está disponível, e nem possui informações a seu respeito. Por este motivo, o sexto mundo foi deixado de fora da tabela. A figura 1 ilustra a interface do jogo. 


\section{CBIE-LACLO 2015}

Anais dos Workshops do IV Congresso Brasileiro de Informática na Educação (CBIE 2015)

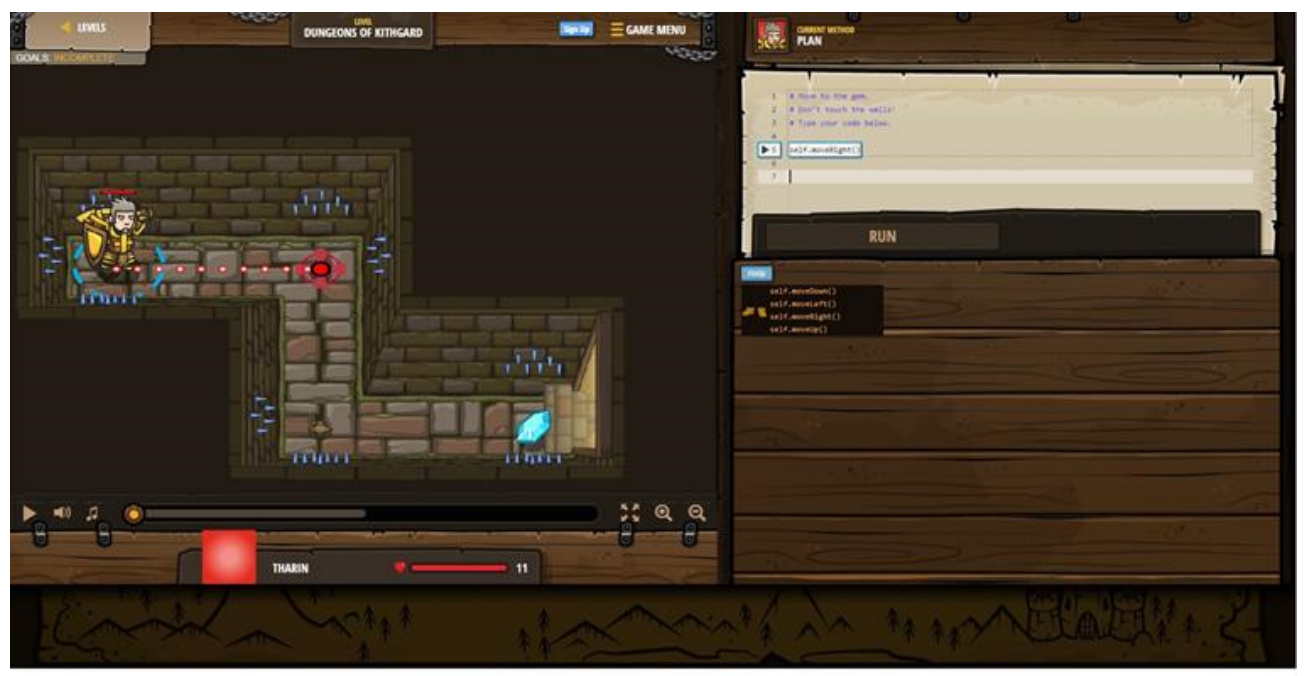

Figura 1. Interface do Code Cobat

A interface do jogo, ilustrada na figura 1, mantém a IDE para digitar o código das soluções sempre no canto direito da tela. Os objetivos e dicas estão sempre escritos em azul no início do código, em forma de comentário. Abaixo da IDE, estão dispostos todos os métodos que podem ser utilizados pelo jogador. Em caso de dúvida, basta o jogador passar o mouse sobre os métodos e uma caixa de diálogo se abrirá com uma explicação. O jogo possui um botão de ajuda, que leva o jogador a uma tela com tutoriais em vídeo sobre a fase em questão.

\subsubsection{Light Bot}

O Light Bot é um jogo de programar que utiliza uma notação de blocos de comando. $\mathrm{O}$ jogo aborda, além dos conceitos de lógica, conceitos de funções. Com o objetivo de programar um robô para acender a luz de todas as plataformas de cor azul disponíveis no nível, o jogador tem à sua disposição uma interface com poucas informações, conforme ilustrada na figura 2.

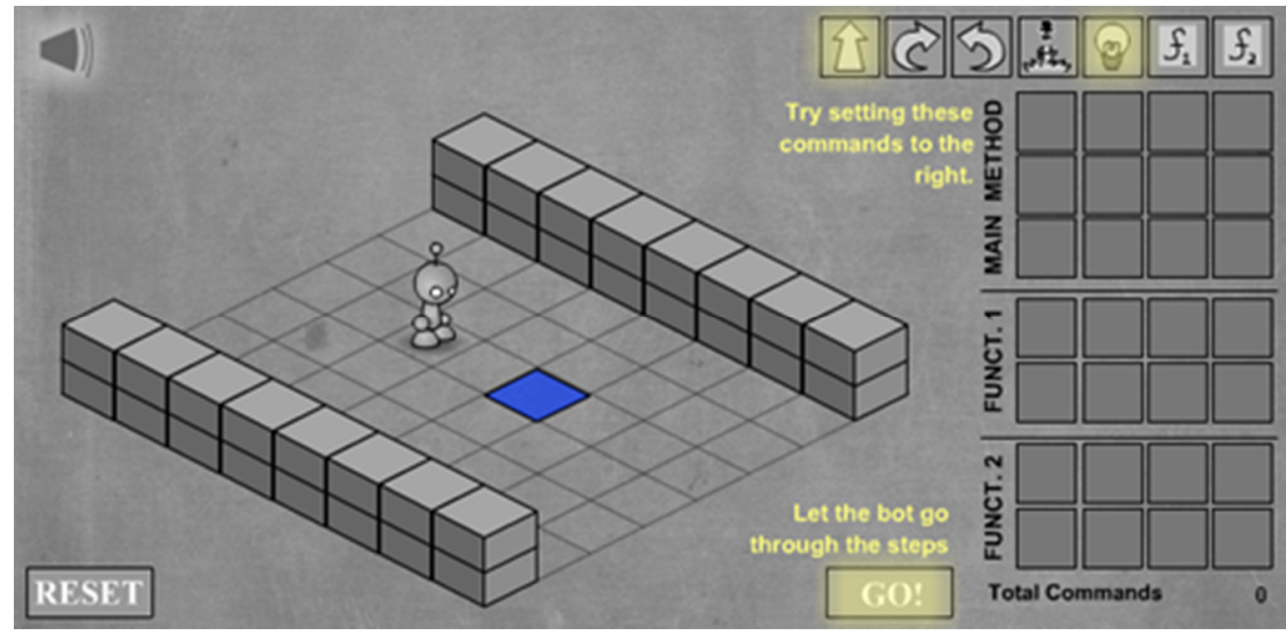

Figura 2. Interface do Lightbot

Os espaços (slots) do lado direito servem para o jogador arrastar os blocos de comando localizados na parte de cima da interface, posicionando-os de forma a solucionar os problemas. A única forma de tutorial que o jogo fornece é destacando com uma luz amarela novos comandos, que ainda não haviam sido utilizados. Juntamente com o 


\section{CBIE-LACLO 2015}

Anais dos Workshops do IV Congresso Brasileiro de Informática na Educação (CBIE 2015)

destaque de comandos, o jogo fornece uma frase de auxílio nas fases iniciais que fica junto da grade de comandos. Os comandos são representados por símbolos. Estão a disposição do jogador os seguintes comandos: andar para frente, virar para a esquerda, virar para a direita, acender, invocar a função 1, invocar a função 2, pular para frente.

Os desafios do jogo se baseiam em acender todas as luzes, criando um algoritmo, que possui um tamanho máximo estipulado pelos slots disponíveis. $\mathrm{O}$ jogador dispõe de três conjuntos de slots para onde é possível arrastar os blocos de comando. O primeiro é o método principal, que pode receber até doze blocos de comandos. O segundo e terceiro são denominados de função 1 e função 2, que podem receber até oito blocos de comando cada um.

\subsubsection{NoBug's Snack Bar}

O NoBug's Snack Bar é um jogo que utiliza a notação de blocos de comandos como no Scratch. É um jogo em desenvolvimento que adota a mesma tecnologia do projeto Code.org do governo norte-americano (Vahldick et. al, 2015).

Atualmente o jogo tem 16 missões com assuntos como sequenciamento de comandos, manipulação de variáveis e condicionais. O jogador assume o papel do atendente de uma lanchonete e programa o comportamento do seu personagem para satisfazer os pedidos dos clientes. Os comandos fazem o personagem ir ao cliente, obter informações sobre o pedido, ir aos locais onde se preparam ou pegam as comidas e bebidas, e entregar os pedidos.

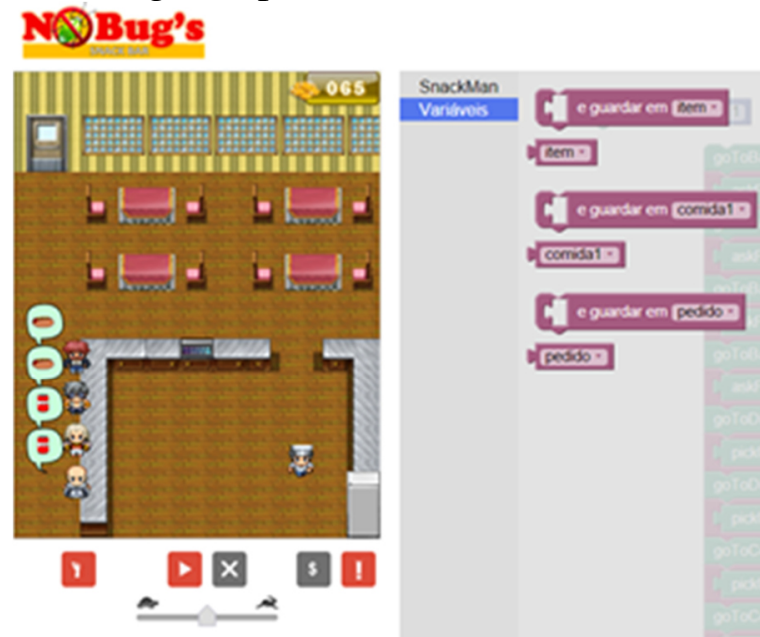

Figura 3. Interface do NoBug's Snack Bar

Existem missões em que o jogador constrói a solução toda, outras em que são introduzidos alguns blocos que serão utilizados na solução final, e ainda missões em que são disponibilizados todos os blocos da solução para o jogador ordená-los. Algumas missões tem restrições quanto à quantidade de blocos e variáveis a serem usadas na solução. Outras fornecem bônus de pontuação se resolver o problema dentro de um limite de tempo. À medida que o jogador avança, o jogo fornece novos comandos. Se o jogador ficar inativo por alguns segundos, principalmente nas primeiras missões, o jogo apresenta dicas de uso de suas ferramentas tal como em um tutorial. O jogo possui recursos de depuração, permitindo que o jogador execute um comando por vez e visualize o estado das variáveis. 
O jogo também apresenta três tipos diferentes de ranqueamento: por quantidade de pontos, pelo tempo total gasto em todas as missões, e pelo total de tentativas para finalizar as missões. Isso cria um ambiente de motivação entre os jogadores através da competição pela mera comparação, pois esses recursos não fornecem pontuações extras ou qualquer outro tipo de bonificação. Como são três tipos de ranqueamento, os jogadores podem ajustar a sua estratégia de resolução de acordo com o ranking que pretendem melhorar. Por exemplo, o ranking pela quantidade de tentativas promove o jogador que tenta resolver através de testes de mesa.

\subsection{Mensuração}

Para mensurar as opiniões dos estudantes a respeito dos jogos, foi elaborado um questionário com perguntas gerais sobre o perfil dos estudantes e sobre a percepção de aprendizagem e da dificuldade em aprender a programar. As perguntas específicas foram respondidas para cada um dos três jogos e referem-se ao estilo tutorial e à percepção de diversão, além de três perguntas abertas. Dois tipos de escala de resposta foram usadas nas questões objetivas: (i) escalas dicotômicas (sim/não); (ii) escalas de diferencial semântico (intervalos de 1 a 5), onde em alguns casos o valor 1 representou sempre uma percepção mais negativa e o valor 5 uma percepção mais positiva conforme exemplifica a figura 4.

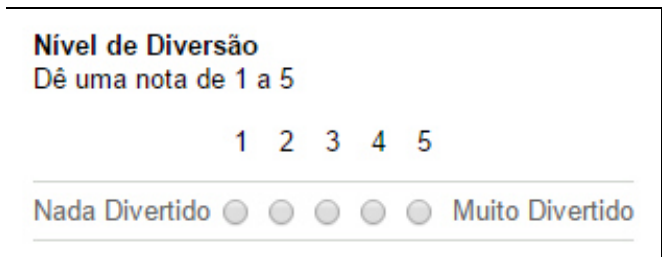

Figura 4. Exemplo de escala utilizada

Outra interpretação para a escala de 5 níveis também foi adotada para questões em que o nível intermediário (3) era o desejável. Por exemplo, uma questão sobre o ritmo em que os desafios evoluem teve a opção intermediária como sendo a mais positiva (ritmo adequado) e os níveis 5-muito rápido ou 1-muito lento como sendo negativos.

As escalas foram todas equilibradas contendo o mesmo número de itens ligados à percepção positiva, negativa e um item neutro. $\mathrm{O}$ quadro 1 ilustra as questões do questionário e suas respectivas escalas.

\begin{tabular}{|l|l|}
\hline Perguntas Gerais \\
\hline Perfil & $\begin{array}{l}\text { Sexo (M ou F) } \\
\text { Possuía algum contato anterior com programação? (sim/não) }\end{array}$ \\
\hline $\begin{array}{l}\text { Conceitos de } \\
\text { programação e } \\
\text { percepção } \\
\text { sobre } \\
\text { programar }\end{array}$ & $\begin{array}{l}\text { Você acha que programar é dificil? (escala de 1-5) } \\
\text { Você entendeu o que é uma "função"? (sim/não) }\end{array}$ \\
& $\begin{array}{l}\text { Você entendeu o que é um "loop"?(sim/não) } \\
\text { Dos jogos testados, qual achou mais divertido? }\end{array}$ \\
& $\begin{array}{l}\text { Baseado na experiência com os jogos, você gostaria de estudar programação? } \\
\text { (sim/não) }\end{array}$ \\
\hline Perguntas Específicas (respondidas para cada jogo)
\end{tabular}

Quadro 1 - Questões do questionário aplicado na pesquisa 


\section{CBIE-LACLO 2015}

Anais dos Workshops do IV Congresso Brasileiro de Informática na Educação (CBIE 2015)

O questionário foi implementado na ferramenta Google Forms e foi respondido pelos estudantes via web no mesmo ambiente onde as atividades do projeto de extensão foram realizadas. O tempo médio de preenchimento dos questionários foi 25 minutos.

\section{Resultados}

As questões fechadas foram tabuladas e sintetizadas em gráficos e tabelas. E as questões abertas foram analisadas principalmente para auxiliar a compreensão dos escores numéricos.

Dos quatorze estudantes que participaram da pesquisa apenas um tinha contato prévio com programação. As questões referentes ao estilo tutorial e à diversão que estavam em uma mesma escala foram somadas para formar um escore. Já a questão referente ao ritmo que os desafios evoluem foi codificada da seguinte forma: 2 pontos para a opção "3-ritmo adequado"; 1 ponto para as opções "4-ritmo acelerado" e "2ritmo lento"; e 0 pontos para as opções "5- ritmo muito acelerado" e "1-ritmo muito lento". O escore calculado permite comparar os três jogos utilizados, conforme apresenta a tabela 1 .

\begin{tabular}{ccc}
\hline Jogo & Estilo tutorial & Diversão \\
\hline Code Combat & 186 & 106 \\
\hline Light Bot & 164 & 116 \\
\hline NoBug's Snack Bar & 183 & 85 \\
\hline
\end{tabular}

Tabela 1- Escores de estilo tutorial e diversão

Nota-se que o estilo tutorial dos jogos Code Combat e NoBug's Snack Bar agradou mais aos estudantes, pois ambos fornecem explicações textuais e dicas durante a realização dos desafios. O Light Bot não é muito explicativo. O resultado da tabela 1 é corroborado pela pergunta específica que pedia aos estudantes para indicarem o jogo mais divertido. A Figura 5 ilustra que não houve diferença entre Code Combat e Light Bot e que o NoBug's Snack Bar foi apontado como o menos divertido.

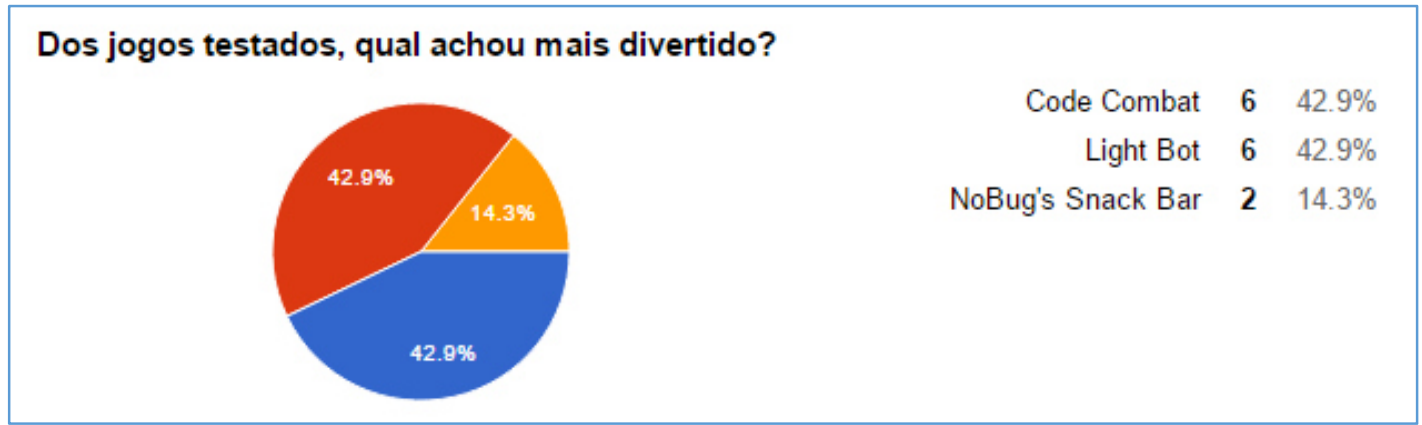

Figura 5. Gráfico sobre qual jogo os estudantes julgaram mais divertido

Com base nas respostas das perguntas abertas foi possível compreender melhor os escores indicados. A facilidade de uso do Code Combat deve-se às suas mecânicas que conduzem o jogador, deixando a dificuldade para os desafios propostos. Por outro lado, a repetição de objetivos acaba tornando o processo monótono para alguns, códigos de difícil compreensão acabaram impactando no nível de divertimento e no ritmo em que os desafios evoluem, dificuldades com o idioma inglês também foram relatadas.

Com relação ao Lightbot, a análise das respostas abertas mostrou que a maior dificuldade foi compreender inicialmente a forma de organizar os comandos, se na vertical, ou na horizontal, e quando usar funções ou apenas o método principal, visto 


\section{CBIE-LACLO 2015}

Anais dos Workshops do IV Congresso Brasileiro de Informática na Educação (CBIE 2015)

que o jogo não apresenta um tutorial muito claro a respeito. Este foi o único jogo que obteve dos alunos um feedback negativo em relação à quantidade de explicações fornecidas ao jogador. A velocidade em que os desafios evoluem também foi identificada como a mais alta entre os três jogos testados.

Nas respostas do NoBug's Snack Bar, a facilidade para aprender a jogar ficou abaixo do Code Combat. Entretanto, o resultado que mais se diferenciou dos demais, foi o nível de diversão, e do envolvimento com o jogo, onde o NoBug's Snack Bar obteve as piores notas entre os três jogos. O mais evidente mencionado foram que as fases se tornavam repetitivas, e por consequência o jogo ficava monótono. Esse jogo insere um conceito por vez em cada missão, se tornando o jogo mais lento quanto ao ritmo em que os desafios são apresentados. Assim como no Code Combat, também foram citados problemas com os comandos serem em idioma inglês. O ambiente de edição do programa necessita de melhorias pois em certas missões, com a exigência de mais código, torna-se difícil a visualização do programa.

As questões gerais possibilitaram analisar o processo de compreensão dos conceitos de programação pelos estudantes, após terem jogados os três jogos. Ainda que alguns jogos não apresentassem estes conceitos explicitamente, o intuito não era comparar os jogos, mas sim avaliar a abordagem de introdução à programação por meio de jogos de programar. Com relação aos conceitos de programação envolvidos a Tabela 2 sintetiza as respostas.

\begin{tabular}{ccc}
\hline Pergunta & Sim & Não \\
\hline Você entendeu o que é uma função? & $13(92.9 \%)$ & $1(7.1 \%)$ \\
\hline Você entendeu o que é um loop? & $13(92.9 \%)$ & $1(7.1 \%)$ \\
\hline Você entendeu o que é uma variável? & $10(71.4 \%)$ & $4(28.6 \%)$ \\
\hline
\end{tabular}

Tabela 2- Compreensão dos conceitos de programação

Pode-se verificar que conceitos normalmente mais avançados no contexto de disciplinas introdutórias, como loops e funções são conceitos em que os estudantes apresentam mais segurança em comparação com um conceito geralmente inicial que é o de variáveis. Este aspecto está ligado à dinâmica dos jogos que reduzem parte dos desafios à construção de soluções com variáveis pré-estipuladas ou então implícitas (como por exemplo o passo do robô no Light Bot), desta forma reduzindo o contato do estudante com este conceito. Também representa a viabilidade de abordar estes conceitos sem necessariamente ver outros que são com frequência considerados prérequisitos como operações relacionais e lógicas.

Com relação à percepção quanto a dificuldade e de programar a figura 6 apresenta os resultados da pergunta correlata.

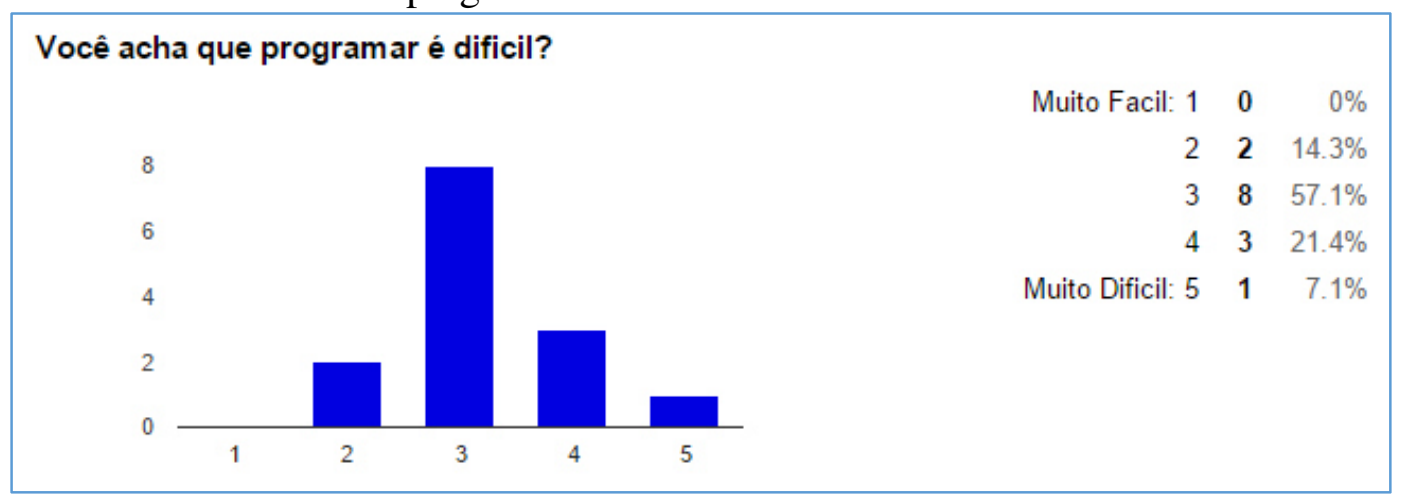

Figura 6 - Percepção sobre dificuldade de programar 


\section{CBIE-LACLO 2015}

Anais dos Workshops do IV Congresso Brasileiro de Informática na Educação (CBIE 2015)

Nota-se que predomina uma percepção de que a dificuldade é média. Esta resposta fornece um indício interessante de que a abordagem com jogos pode auxiliar os estudantes a perderem o temor tradicionalmente relatado em pesquisas de aprendizagem de programação. A percepção da dificuldade está fortemente relacionada à ansiedade, que produz efeitos negativos na aprendizagem de programação (Connolly et al., 2009; Chang, 2004).

Dos 14 estudantes, 13 (92,9\%) indicaram que gostariam de estudar programação. Este resultado fornece outro indício que defende o uso da abordagem de jogos de programar nos contatos iniciais dos estudantes com conceitos de programação

\section{Conclusões}

Ao analisar os resultados obtidos nesta pesquisa pode-se identificar que, apesar de utilizar a notação textual considerada por diversos autores como uma notação intimidadora à primeira vista, o Code Combat teve o melhor escore com relação à facilidade para aprender a jogar e teve um alto escore de estilo tutorial. Por ser um resultado com uma pesquisa de amostra pequena e enviesada (estudantes foram escolhidos pela escola por desempenho), não se afirma que esta característica ocorra em outros contextos, mas é um indício que motiva a realização de uma futura investigação mais direcionada a avaliar o impacto proporcionado pelas diferentes notações de programação nos contatos iniciais dos estudantes.

A diversão é um elemento importante, pois possibilita ampliar o engajamento e a motivação que são elementos fundamentais para facilitar a aprendizagem. O Lightbot obteve as maiores pontuações para diversão e para o nível de envolvimento com o jogo, sendo que na última ficou empatado com o Code Combat.

Observou-se também que o NoBug's Snack Bar obteve o pior resultado em relação ao divertimento e ao nível de envolvimento com o jogo, indicando que o estilo tutorial utilizado (bastante explicativo) pode criar um ambiente menos atrativo. $\mathrm{O}$ equilíbrio entre diversão e instrução é um desafio permanente no projeto de software educacional e o mesmo vale para os jogos de programar.

Os estudantes relataram terem compreendido os conceitos de funções e loops de forma mais sólida do que o conceito de variável. Este resultado também é um indício que necessita ser investido em amostras maiores e que pode indicar que a ordem geralmente sugerida pelos livros didáticos de algoritmos e programação é passivel de revisão. Isto reflete também a natureza dos jogos que buscam dar algum significado imediato à solução que o estudante está criando no contexto do jogo, elemento que muitas vezes está ausente nas explicações feitas por professores em sala de aula e que pode ser fonte de desinteresse (Zanini e Raabe, 2012).

A tarefa de programar não foi vista como difícil, mas como uma tarefa de média dificuldade. A grande maioria das respostas foi favorável quando perguntado aos alunos se gostariam de estudar programação. Estes resultados indicam que a abordagem de uso de jogos de programar nos contatos iniciais dos estudantes podem trazer resultados benéficos ao criar um ambiente menos intimidador em que o estudante se percebe capaz de atingir seus objetivos educacionais enquanto se diverte.

As perspectivas futuras desta pesquisa incluem ampliar a coleta das opiniões dos estudantes com a realização de entrevistas e grupos focais. O foco estará em elucidar mais profundamente as características dos jogos que favoreceram ou dificultaram o aprendizado dos conceitos iniciais de Computação e impactaram na motivação para aprender a programar. 


\section{Agradecimentos}

AV agradece a bolsa de doutorado apoiada pelo CNPq/CAPES - Programa Ciência sem Fronteiras - CsF (6392-13-0) e autorização de afastamento da UDESC (688/13). Os autores também agradecem a disponibilidade e participação dos alunos envolvidos no experimento.

\section{Referências}

CHANG, S.E. Computer anxiety and perception of task complexity in learning programming-related skills. Computers in Human Behaviour. 21, 713-728, 2004

CONNOLLY, C.; MURPHY, E. and MOORE, S. Programming Anxiety amongst Computing Student - A Key in Retention Debate?, IEEE Transactions on Education, vol. 52, no. 1, pp.52 -56, 2009

DE JESUS, E. A.; RAABE, A. L. A. Avaliação Empírica da Utilização de um Jogo para Auxiliar a Aprendizagem de Programação. In: XXI Simpósio Brasileiro de Informática na Educação, 2010, João Pessoa. Anais do ... Simpósio Brasileiro de Informática na Educação, 2010. v. 1. p. 10-20.

GOMES, A.; MENDES, J. A. Learning to program - difficulties and solutions CompSysTech International Conference on Engineering Education - ICEE, 2007.

KINNUNEM, P.; MC CARTNEY, R.; MURPHY, L.; THOMAS, L. Through the eyes of instructors: a phenomenographic investigation of student success. Proceedings of the third international workshop on Computing education research. p 61-72, 2007

OREHOVAČKI, T.; BABIĆ, S. Inspecting Quality of Games Designed for Learning Programming. Lecture Notes in Computer Science - 17th International Conference on Human-Computer Interaction, 2015.

ROGERSON, C.; SCOTT E. The Fear Factor: How It Affects Students Learning to Program in a Tertiary Environment. Journal of Information Technology Education v 9, 2010.

VAHLDICK, A.; MENDES, A.J.; MARCELINO, M.J., "A review of games designed to improve introductory computer programming competencies," Frontiers in Education Conference (FIE), 2014 IEEE, vol., no., pp.1,7, 22-25 Oct. 2014.

VAHLDICK, A.; MENDES, A. J.; MARCELINO, M.J.P.; HOGENN, M.; SCHOEFFEL, P. Testando a Diversão em um Jogo Sério para o Aprendizado Introdutório de Programação, in $23^{\circ}$ WEI - Workshop sobre Educação em Computação, (XXXV Congresso da Sociedade Brasileira de Computação), 2015.

ZANINI, A. S.; RAABE, A. L. A. Análise dos enunciados utilizados nos problemas de programação introdutória em cursos de Ciência da Computação no Brasil. In: WEI - XX Workshop sobre Educação em Computação, 2012, Curitiba. XXX Congresso da Sociedade Brasileira de Computação. Curitiba: SBC, 2012. 